Article

\title{
Combination of the Experimental and Theoretical Approaches for the Estimation of the C1-C4 Alkane Permeability Parameters in Poly (4-Methyl-2-Pentyne) and Poly (4-Methyl-1-Pentene)
}

\author{
Svetlana Markova ${ }^{1, *}$, Vyacheslav Zhmakin ${ }^{1,2}$, Thomas Gries ${ }^{3}$ and Vladimir Teplyakov ${ }^{1}$ \\ 1 TIPS RAS, 29 Leninskiy Prospect, 119991 Moscow, Russia; vyacheslav.zhmakin@gmail.com (V.Z.); \\ tepl@ips.ac.ru (V.T.) \\ 2 Sechenov First State Medical University, 8/2 Trubetskaya Street, 119991 Moscow, Russia \\ 3 Institut für Textiltechnik der RWTH Aachen University, Otto-Blumenthal-Str. 1, 52074 Aachen, Germany; \\ thomas.gries@ita.rwth-aachen.de \\ * Correspondence: markova@ips.ac.ru
}

Received: 23 January 2020; Accepted: 27 February 2020; Published: 3 March 2020

check for updates

\begin{abstract}
Poly (4-methyl-2-pentyne) (PMPentyne) and poly (4-methyl-1-pentene) (PMPentene) as membrane gas-separating media were studied with a combination of experimental and theoretical approaches. Experimental approaches included the permeability measurements for $C_{1}-C_{4}$ alkanes in linear heating mode (for PMPentyne) and under isothermal conditions (for PMPentene), and diffusivity evaluation by a differential method for PMPentene. Theoretical approaches included the 'hard-spheres' theory for calculation of gas solubility in PMPentyne and gas transport theory for two-phase systems for the estimation of the amorphous and crystalline phases contribution in PMPentene. Correlation analysis was used for any type of gas transfer parameter calculation where experimental data were lacking. These combinations of methods allowed obtaining the whole set of parameters for any gas-polymer pairing and explained the butane-selective properties revealed in PMPentyne $\left(C_{1}<C_{2}<C_{3}<C_{4}\right)$ and methane-selective properties of PMPentene $\left(C_{1}>C_{2}>C_{3}>C_{4}\right)$.
\end{abstract}

Keywords: poly (4-methyl-2-pentyne); poly (4-methyl-1-pentene); $C_{1}-C_{4}$ alkanes; selective gas transport

\section{Introduction}

Poly (4-methyl-2-pentyne) and poly (4-methyl-1-pentene) are prospective membrane materials for the separation of lower-hydrocarbon-containing gaseous mixtures. Both these polymers are usually abbreviated to PMP in the literature. Here, to distinguish one from another we will write them as PMPentyne and PMPentene accordingly throughout the article.

PMPentene is a semicrystalline polymer with $\mathrm{T}_{\mathrm{g}} \sim 30^{\circ} \mathrm{C}$ and $\mathrm{T}_{\mathrm{m}} \sim 235^{\circ} \mathrm{C}$. Physical density is $\sim 0.83 \mathrm{~g} / \mathrm{cm}^{3}$. Free volume fraction (FFV) is 0.186 [1]. The crystalline phase of PMPentene is permeable to gases, and it has practically the same physical density as the amorphous phase [2-4]. It occupies a special place among commercially available polymers [2,5]. PMPentene is a medium-permeable polymer with a history of application as a membrane material. PMPentene-based membranes are used mostly for medical purposes in oxygenators [6]. Melt-spinning technology is used for hollow fiber production. It should be noted that previous production of PMPentene hollow fibers with homogenous walls was performed in Russia at NPO 'Khimvolokno' [7]. Currently, on an industrial scale PMPentene is manufactured by Mitsui Chemical, Inc. under the trademark TPX, including hollow fiber gas separation membranes. Note that PMPentene is one of the most permeable commercially 
used membrane polymers. The permeability of PMPentene towards several different gases is shown in Table 1.

PMPentyne is a glassy hydrocarbon-based 1, 2-disubstituted polyacetylene. It has density of $\sim 0.8 \mathrm{~g} / \mathrm{cm}^{3}$ [8] with high free volume fraction (FFV value is 0.28 [9]) and very high glass transition temperature $\left(\mathrm{T}_{\mathrm{g}}>250^{\circ} \mathrm{C}\right)$ [9]. Usually, thermodestruction of polymers of this type starts at temperatures lower than $\mathrm{T}_{\mathrm{g}}$. This type of polymer is more permeable to larger hydrocarbons (e.g., butane) than to smaller molecules (e.g., nitrogen). PMPentyne can be used for laboratory-scale flat-sheet composite membranes [10]. The gas permeability characteristics of the polymer are shown in Table 1.

Table 1. Permeability coefficients of PMPentene and PMPentyne in relation to certain gases.

\begin{tabular}{ccccccc}
\hline \multicolumn{7}{c}{ Permeability $p$, Barrers } \\
\hline Polymer & $\mathbf{H}_{\mathbf{2}}$ & $\mathbf{H e}$ & $\mathbf{N}_{\mathbf{2}}$ & $\mathbf{O}_{\mathbf{2}}$ & $\mathbf{C O}_{\mathbf{2}}$ & $\mathbf{C H}_{\mathbf{4}}$ \\
\hline PMPentene $\left(25^{\circ} \mathrm{C}\right)[$ present work] & $125\left(35^{\circ} \mathrm{C}\right)[4]$ & 80.2 & 7.6 & 27.5 & 84.0 & 12.7 \\
PMPentyne $\left(35^{\circ} \mathrm{C}\right)[11]$ & 3500 & $2500[12]$ & 800 & 1700 & 7500 & 2000 \\
\hline
\end{tabular}

Both these polymers are stable to lower hydrocarbons and can be used for hydrocarbon-containing gas mixture separation. It is known that PMPentene is characterized in terms of $C_{1}-C_{4}$ permeability as a conventional glassy polymer $\left(C_{1}>C_{2}>C_{3}>C_{4}\right)$ [13]. In contrast, PMPentyne shows the opposite permeance behavior $\left(C_{1}<C_{2}<C_{3}<C_{4}\right)$ [14]. PMPentyne has a peculiarity, which is that its very high gas diffusivity makes direct experimental measurements of diffusion coefficients impossible. The current study is dedicated to combining experimental and theoretical approaches to the estimation of the permeability parameters for gas separation membranes based on glassy and rubber-like polymers. The paper demonstrates an example of the approaches combination for PMPentene and PMPentyne in order to be able to consider the full set of gas separation parameters. This combination allows such types of evaluation whether for homogeneous films of highly permeable polymers or for ultrathin membranes (the cases of very low time-lag values).

\section{Materials and Methods}

\subsection{Materials}

PMPentene films with crystallinity degree $\left(X_{c}\right)$ of 0.69 were used. The polymer for the film was made by suspension polymerization of 4-methyl-1-pentene in the A.V. Topchiev Institute of Petrochemical Synthesis, Russian Academy of Sciences (TIPS RAS). The PMPentene film (laboratory sample) was obtained by the film extrusion method in laboratory 'Polymer composites and adhesives' in TIPS RAS. The sample thickness was $50 \pm 2 \mu \mathrm{m}$. The chemical structure of poly (4-methyl-1-pentene) is shown in Figure 1.

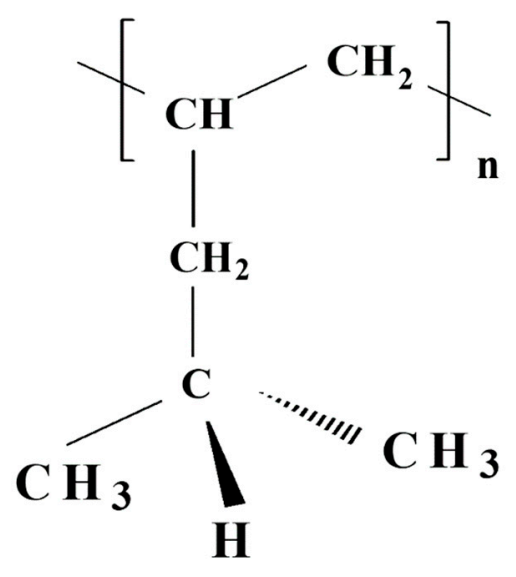

Figure 1. Repeating unit of PMPentene. 
PMPentyne films used for the study were also developed in TIPS RAS. Figure 2 shows the chemical structure of poly (4-methyl-2-pentyne). It should be noted that PMPentyne possesses cis/trans microstructure. In our case cis/trans relation was $40 / 60 \%$ [11]. The permeability coefficients of certain gases through PMPentyne are set out in Table 1. PMPentyne films were prepared by casting from a polymer solution in high-purity cyclohexane (99.9\%). The thickness of the films was approximately $41 \pm 3 \mu \mathrm{m}$. The experimental study began on the 90th day after film preparation, in order to avoid the strong effect of aging on the membrane properties and to achieve stable results.

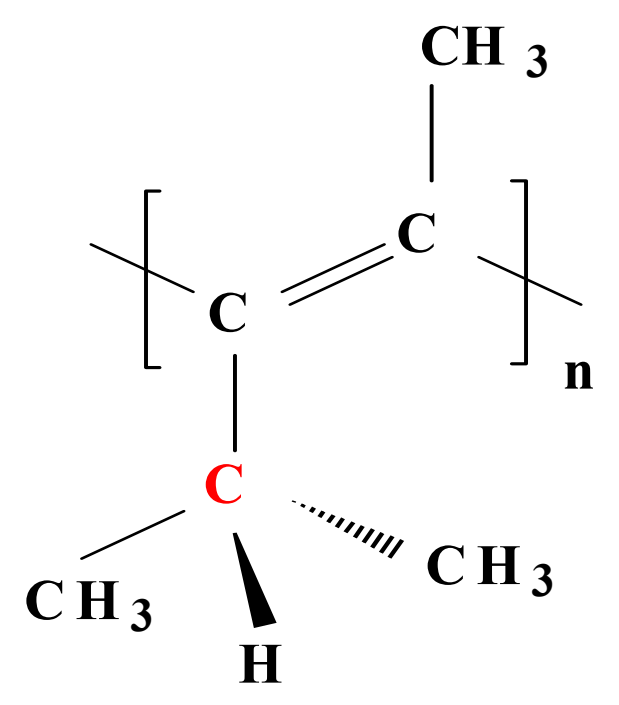

Figure 2. Repeating unit of PMPentyne.

The gases studied were used directly from the pressure cylinders, without any primary treatment. The gases studied had a purity higher than $99 \%$. Nitrogen $(99.999 \%)$, helium $(99.999 \%)$, methane $(99.9 \%)$, and n-butane $(99.75 \%$ ) were manufactured by Monitoring LLC (Zelenograd, Russia), ethane $(99.9 \%)$ by Scott Specialty Gases (Breda, the Netherlands) and propane (99.9\%) by Linde Gas (Balashikha, Russia).

\subsection{Gas Permeability Measurements}

The experimental unit scheme is presented in Figure 3. The polymer film was hermetically fixed in the membrane cell, which was located in a thermocryostat (Huber CC-410) that allowed the experiment to be carried out in the temperature range -20 to $140{ }^{\circ} \mathrm{C}$. The membrane (film) divided the volume of the cell into two cavities: the reservoir (feed side) and the receiver (permeate side). The gas to be studied was supplied on the feed side at 1 atmosphere at a flow rate of 1-2 mL/s. The carrier gas (helium or argon) was supplied on the permeate side with the same flow rate for the experiments without evacuation (experiments with PMPentene). For the experiments with significant amounts of condensable components (butane) and all the experiments with PMPentyne, continuous evacuation of the permeate side by a flow vacuum pump (ASF Thomas) was applied (stage cut did not exceed 0.1). The partial pressure drop across the membrane in both cases was kept at $\sim 1$ atmosphere. For the second case, further dilution of the permeate sample with carrier gas was applied. Chromatographic analysis of a permeate sample diluted with helium was conducted on a Shimadzu GC-17 chromatograph (Kyoto, Japan) with a thermal conductivity detector (TCD 1) and capillary column (GS-Tek 8253-5015) allowing for the analysis of mixtures of $C_{1}-C_{5}$ hydrocarbons (saturated, unsaturated, isomers) with helium as carrier gas. As PMPentyne is a highly permeable polymer with low time-lag values $(\theta \approx 0.01-0.1 \mathrm{~s})$, it was possible to carry out gas permeation measurements under slow linear heating of the membrane cell $\left(0.3^{\circ} \mathrm{C} / \mathrm{min}\right)[15]$. 


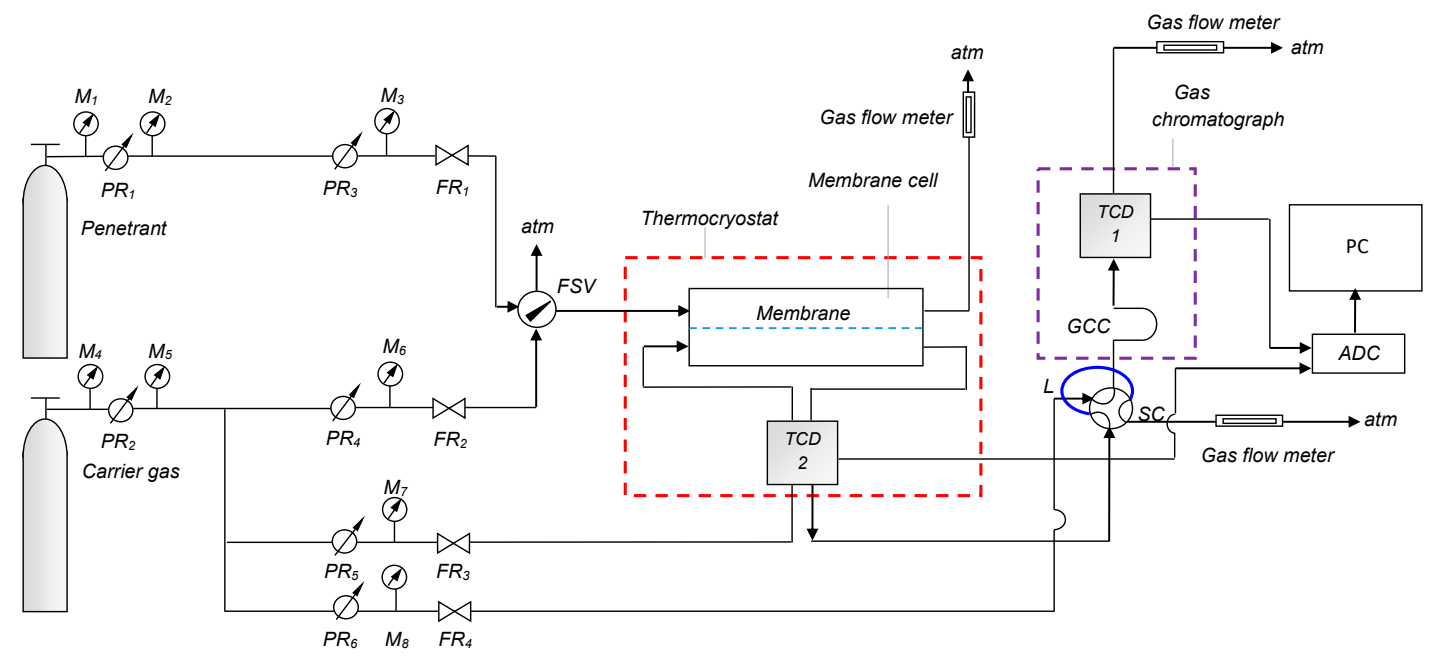

Figure 3. Experimental setup for permeability and diffusion coefficients measurements: TCD—Thermoconductivity Detector; GCC—Gas Chromatographic Column; L-Loop, SC—Sampling Cock; PC—Personal Computer; ADC—Analog-to-Digital Converter; M-Manometer; PR—Pressure Regulator; FR-Flow Regulator; FSV—Flow Switch Valve.

The gas permeability coefficient $(p)$ was calculated according to the equation:

$$
P_{i}=\frac{V c_{i}^{\prime} l}{A\left(p_{1} c_{i}-p_{2} c_{i}^{\prime}\right)^{\prime}},
$$

where $V$ is the flow rate of the gas carrier with the penetrant, $\mathrm{cm}^{3}$ (STP) $\mathrm{s}^{-1} ; A$ is the membrane area, $\mathrm{cm}^{2} ; p_{1}$ is the feed pressure, $\mathrm{cmHg} ; p_{2}$ is the permeate pressure, $\mathrm{cmHg} ; c_{i}$ is the concentration of the penetrant in the feed flow, $\mathrm{vol} \% ; c_{i}{ }^{\prime}$ is the concentration of the penetrant in the gas carrier stream in the permeate, $\mathrm{vol} \%$; and $l$ is the membrane (film) thickness, $\mathrm{cm}$.

It is known that the gas separation selectivity $\alpha_{P_{i j}}\left(\alpha_{P_{i j}}=P_{i} / P_{j}\right)$ includes $\alpha_{D_{i j}}$ (selectivity of diffusion, $\alpha_{D_{i j}}=D_{i} / D_{j}$ ) and $\alpha_{S_{i j}}$ (selectivity of gas solubility, $\alpha_{S_{i j}}=S_{i} / S_{j}$ ), which depends on temperature. For this reason, we needed to determine all key permeability parameters at the required temperatures.

The diffusion coefficients $(D)$ were determined by the differential permeability method. In this method, the time dependence of the unsteady penetrant flow through the membrane, with a stepwise change in concentration on the upstream side of the membrane, was registered online. The aim of the method is to obtain the differential permeability curve by TCD 2 and to carry out its subsequent processing by using the functional scale method [16].

The experimental gas transport parameter measurements were carried out in the temperature range -20 to $80^{\circ} \mathrm{C}$ for PMPentene and -20 to $40{ }^{\circ} \mathrm{C}$ for PMPentyne (from $0{ }^{\circ} \mathrm{C}$ for butane). In the case of PMPentyne the data for $80^{\circ} \mathrm{C}$ were extrapolated from the experimental data.

\section{Theoretical Approaches}

Three theoretical approaches were used throughout the study: (1) gas transport estimation in two-phase systems; (2) gas solubility estimation using 'hard-spheres' theory; and (3) correlation analysis of the gas permeability parameters.

\subsection{Two-Phase System}

For the case of selective gas transfer in two-phase systems (such as semicrystalline PMPentene) selective gas transfer theory can be applied. Calculation of the diffusion coefficients in the amorphous and crystalline PMPentene phases was performed based on a combination of Maxwell and Fricke equations, which take into account the shape, orientation and mutual influence of particles of the 
dispersed phase. We have previously tested this approach on the diffusion of permanent gases in silane-siloxane block copolymers. The generalized Equation (2) for the calculation of $D$ is as follows $[17,18]$ :

$$
\begin{gathered}
D=f\left(D_{a}, D_{c}, X_{a}, X_{c}, A, Z\right)=\frac{X_{a} D_{a}+k X_{c} D_{c}}{X_{a}+k X_{c}}, \\
k=\frac{1}{3} \sum_{i=1}^{3} \frac{1}{1+\left(\frac{A_{i}}{2}\right)\left(\frac{D_{c}}{D_{a}}-1-\frac{Z}{D_{a}}\right)}
\end{gathered}
$$

where $D_{a}$ and $D_{c}$ are diffusion coefficients in amorphous and crystalline PMPentene phases, respectively, $\left(\mathrm{cm}^{2} / \mathrm{s}\right) ; X_{a}, X_{c}$ are the amorphous and crystalline phase fractions, respectively; $A_{i}$ is the shape parameter of crystallites (dispersed particles) varying from 0 to 1 (for spherical particles $A_{i}=0.66$ ); and $\mathrm{Z}$ is the coefficient introduced for concentrated dispersions, which is defined as the correction of diffusion fluxes taking into account the mutual influence of neighboring particles.

\subsection{Approach to Solubility Coefficient and Sorption Heat Estimation Using 'Hard-Spheres' Model}

A number of gas solubility correlations in liquids and polymers are known. For example, the boiling temperatures and the critical temperatures of gases [19], their Lennard-Jones potentials [12,20], and Van-der-Waals surface areas [21] could be used. The semi-empirical approaches to estimate the gas (vapor) solubility in the polymers are also known [22-25]. The correlation approaches show, for instance, that the gas solubilities in liquids and polymers have a similar origin, and the thermodynamic contribution to selectivity can be pre-calculated $[19,26]$.

We suggest to extend the statistical thermodynamic approach used for the gas-polymer systems earlier [20] for the estimation of $S$ and $\Delta H_{S}$ of the lower hydrocarbons in polymers. The approach is based on the gas solubility analogy in liquids and polymers, setting the monomer unit as an 'active' item of a solvent $[20,27]$.

We defined thermodynamic (solubility coefficient) and kinetic (diffusion coefficient) contributions. To estimate the solubility contribution, we applied the previously used approach [15] for the calculation of the solubility coefficient of the $\mathrm{C}_{1}-\mathrm{C}_{4}$ alkanes and the sorption heat (the 'hard-spheres' theory). For the main equations and some of the results see [27-29].

The Henry constants calculated for $1 \mathrm{~mol}$ of solute is evaluated as follows [30]:

$$
\ln K_{H}=\frac{\bar{G}_{i}}{R T}+\frac{\bar{G}_{c}}{R T}+\ln \left(\frac{R T}{V_{1}}\right)
$$

where $\bar{G}_{i}$ is the partial molar free energy of interaction of the solute and solvent molecules, $\bar{G}_{c}$ is the partial molar free energy of the cavity creation, and $V_{1}$ is the partial molar volume of the solvent (polymer).

The solubility coefficient of the alkanes is linked to Henry's constant $\left(K_{H}\right)$, as shown in Equation (5):

$$
S=\frac{V_{m}}{K_{H} V_{1} p *}
$$

where $V_{m}$ is the molar gas volume, and $P^{*}$ the dissolved gas partial pressure.

It is linked with the sorption heat $\Delta H_{S}$ via Equation (6):

$$
\Delta H_{S}=\left(\frac{\partial \ln K_{H}}{\partial \frac{1}{R T}}\right)_{p}=\bar{H}_{c}+\bar{H}_{i}-R T+\alpha_{p} R T^{2},
$$

where $\bar{H}_{c}$ is the partial molar free enthalpy of cavity creation, $\bar{H}_{i}$ is the partial molar free enthalpy of interaction of solute and solvent molecules, and $\alpha_{p}$ is the coefficient of the thermal expansion of the solvent (polymer). 
Some results obtained using this approach are presented in Table 2 as examples.

Table 2. Solubility parameters calculated for methane and butane in PMPentyne at $25^{\circ} \mathrm{C}$ [31].

\begin{tabular}{ccc}
\hline Parameter & $\mathbf{C H}_{\mathbf{4}}$ & $\mathbf{C}_{\mathbf{4}} \mathbf{H}_{\mathbf{1 0}}$ \\
\hline$S, \mathrm{~cm}^{3} /\left(\mathrm{cm}^{3} \cdot \mathrm{cmHg}\right)$ & 0.025 & 1.49 \\
$\Delta H_{S}, \mathrm{~kJ} / \mathrm{mol}$ & -17.3 & -38.5 \\
\hline
\end{tabular}

\subsection{Correlation Analysis}

The data obtained allowed the use of correlation analysis. The gas permeability coefficient estimation of the PMPentene crystalline phase was performed using a correlation approach $[12,20]$ and available experimental data. Thus, the correlation of the diffusion coefficients $(D)$ with the molecular cross-section is known for the noble gases and several polyatomic gases and is described by Equation (7) as follows:

$$
\log D_{i}=K_{1}-K_{2} d_{e f i}^{2}
$$

The values of the gas solubility coefficient $(S)$ increase exponentially with the Lennard-Jones constant Equation (8) as follows:

$$
\log S_{i}=K_{3}+K_{4}\left(\varepsilon_{i} / k\right)
$$

The general expression for estimating the gas permeability coefficient is described by the following Equation (9):

$$
\log P_{i}=\log D_{i}+\log S_{i}=K_{1}-K_{2} d_{e f i}^{2}+K_{3}+K_{4}\left(\varepsilon_{i} / k\right)
$$

These Equations (7)-(9) can be used in any combination. The gas permeability parameters were calculated for 3D surface, which includes $\geq 3$ parameters for different gases (from the group $P, D$ and $S$ values at a specified temperature) in coordinates of $d_{e f i^{\prime}}^{2}\left(\varepsilon_{i} / k\right)$ and $p$ with employing least squares method. This method was used for the cases where experimental information was lacking (e.g., butane in PMPentene and ethane permeability in PMPentyne).

\section{Results and Discussion}

Diffusivity coefficients for $\mathrm{C}_{1}-\mathrm{C}_{3}$ alkanes in PMPentene were calculated using a two-phase model for amorphous and crystalline phases. The results for the crystalline $\left(D_{c}\right)$ and amorphous $\left(D_{a}\right)$ PMPentene phases are given in Table 3.

Table 3. The gas diffusion coefficients in the amorphous and crystalline phases of PMPentene at different temperatures.

\begin{tabular}{cccc}
\hline $\mathbf{D} \times \mathbf{1 0}^{7}, \mathbf{c m}^{2} / \mathbf{s}$ & $\mathbf{C H}_{\mathbf{4}}$ & $\mathbf{C}_{\mathbf{2}} \mathbf{H}_{\mathbf{6}}$ & $\mathrm{C}_{\mathbf{3}} \mathbf{H}_{\mathbf{8}}$ \\
\hline \multicolumn{5}{c}{$\mathbf{t}=\mathbf{8 0}{ }^{\circ} \mathrm{C}$} & & \\
$D_{a}$ & 8.0 & 7.5 & 5.4 \\
$D_{c}$ & 1.2 & 1.0 & 0.1 \\
& $\mathbf{t}=\mathbf{2 5}{ }^{\circ} \mathrm{C}$ & & \\
$D_{a}$ & 2.7 & 0.38 & - \\
$D_{c}$ & 1.5 & 0.38 & - \\
& $\mathbf{t}=\mathbf{1 0}{ }^{\circ} \mathrm{C}$ & & \\
$D_{a}$ & 1.9 & 0.28 & - \\
$D_{c}$ & 1.3 & 0.26 & - \\
\hline
\end{tabular}

As can be seen from Table $3, D_{c}$ is significantly lower than $D_{a}$ at temperatures above $\mathrm{T}_{\mathrm{g}}$. At the temperatures below $\mathrm{T}_{\mathrm{g}}$ the values of $D_{a}$ and $D_{c}$ are quite close. Detailed explanation of the calculation is done in [18]. Permeability coefficients for amorphous and crystalline phases were obtained from the experimental data using the same approach (Table 4). 
Table 4. The gas permeability coefficients in the amorphous $\left(P_{a}\right)$ and crystalline $\left(P_{c}\right)$ phases of PMPentene at different temperatures.

\begin{tabular}{|c|c|c|c|}
\hline$P$, Barrer & $\mathrm{CH}_{4}$ & $\mathrm{C}_{2} \mathrm{H}_{6}$ & $\mathrm{C}_{3} \mathrm{H}_{8}$ \\
\hline \multicolumn{4}{|c|}{$\mathrm{t}=80^{\circ} \mathrm{C}$} \\
\hline$P_{a}$ & 146 & 135 & 123 \\
\hline$P_{c}$ & 31 & 11.8 & 4.4 \\
\hline \multicolumn{4}{|c|}{$t=25^{\circ} \mathrm{C}$} \\
\hline$P_{a}$ & 11 & 11.8 & - \\
\hline$P_{c}$ & 11 & 11.8 & - \\
\hline \multicolumn{4}{|c|}{$t=10^{\circ} \mathrm{C}$} \\
\hline$P_{a}$ & 9.0 & 7.8 & - \\
\hline$P_{c}$ & 9.0 & 7.4 & - \\
\hline
\end{tabular}

This approach allows estimation of the permeability and diffusion coefficients in the amorphous and crystalline phases as well as the contribution of the amorphous and crystalline phase influence on the gas transport and selective properties of the membranes based on semicrystalline polymers.

The influence of crystallinity degree of PMP on the permeability parameters was investigated in our previous work [18]. It was shown that with increasing crystallinity, the permeability of some gases (namely, lower hydrocarbons) decreases, and at the same time the permeability of helium does not depend on crystallinity. In this case, the separation selectivity for such gas pairs as, for example, helium/methane and methane/butane, increases. In the present paper the theoretical approach to the description of permeability in two-phase systems is proposed as a part of a combined approach for evaluating the contribution of one of the phases (in this case crystalline and amorphous) to the gas transport properties of semicrystalline polymers (or other two-phase systems, such as block copolymers).

As for PMPentyne, there is no direct quantitative method to obtain the gas diffusion coefficients in thin polymeric films (very low values of time-lag). One of the options to estimate the diffusion coefficients is to calculate them taking into account certain permeability coefficients (experimental) and the solubility coefficients (calculated, e.g., using Equations (4)-(6)). According to the experimental ( $p$ and $E_{P}$ ) and the calculated ( $S$ and $\Delta H s$ ) values, the diffusion coefficients $D$ and the diffusion activation energies $E_{D}$ for methane, ethane, propane and n-butane were estimated. The results of this evaluation for methane and butane are presented in Table 5 .

Table 5. Membrane parameters for methane and butane in PMPentyne at $25^{\circ} \mathrm{C}$ [31-33].

\begin{tabular}{ccc}
\hline Parameter & $\mathbf{C H}_{\mathbf{4}}$ & $\mathbf{C}_{\mathbf{4}} \mathbf{H}_{\mathbf{1 0}}$ \\
\hline$S, \mathrm{~cm}^{3} /\left(\mathrm{cm}^{3} \cdot \mathrm{cmHg}\right)$ & 0.025 & 1.49 \\
$P, \mathrm{Barrer}$ & 1500 & 9100 \\
$D, \mathrm{~cm}^{2} / \mathrm{s}$ & $6.0 \times 10^{-6}$ & $6.1 \times 10^{-7}$ \\
$\Delta H_{S}, \mathrm{~kJ} / \mathrm{mol}$ & -17.3 & -38.5 \\
$E_{P}, \mathrm{~kJ} / \mathrm{mol}$ & -8.3 & -25.9 \\
$E_{D}, \mathrm{~kJ} / \mathrm{mol}$ & 9.0 & 12.6 \\
\hline
\end{tabular}

Thus, we fulfilled the estimation of the gas transfer parameters for the $C_{1}-C_{4}$ alkanes through PMPentyne membranes, which allowed a comparative analysis of obtained values for PMPentyne and PMPentene. The results of this comparison at different temperatures $\left(10,25\right.$ and $\left.80^{\circ} \mathrm{C}\right)$ are shown in Figures 4-9. Since the permeability data for ethane in PMPentyne and data for butane in PMPentene were missing, the values used for further calculations and shown in the figures were obtained by correlation approach described in Section 3.3. 


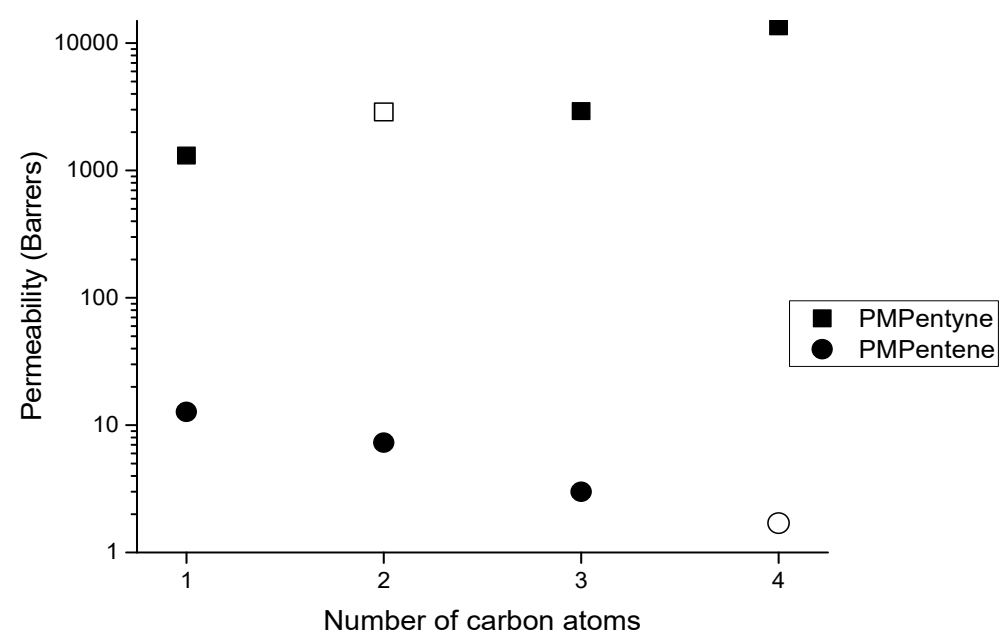

Figure 4. Permeability coefficients of PMPentyne and PMPentene at $10{ }^{\circ} \mathrm{C}: \mathbf{\square}, \bullet$ experimental data; $\square$, $\bigcirc$ data calculated using correlation approach (Equations (7)-(9)).

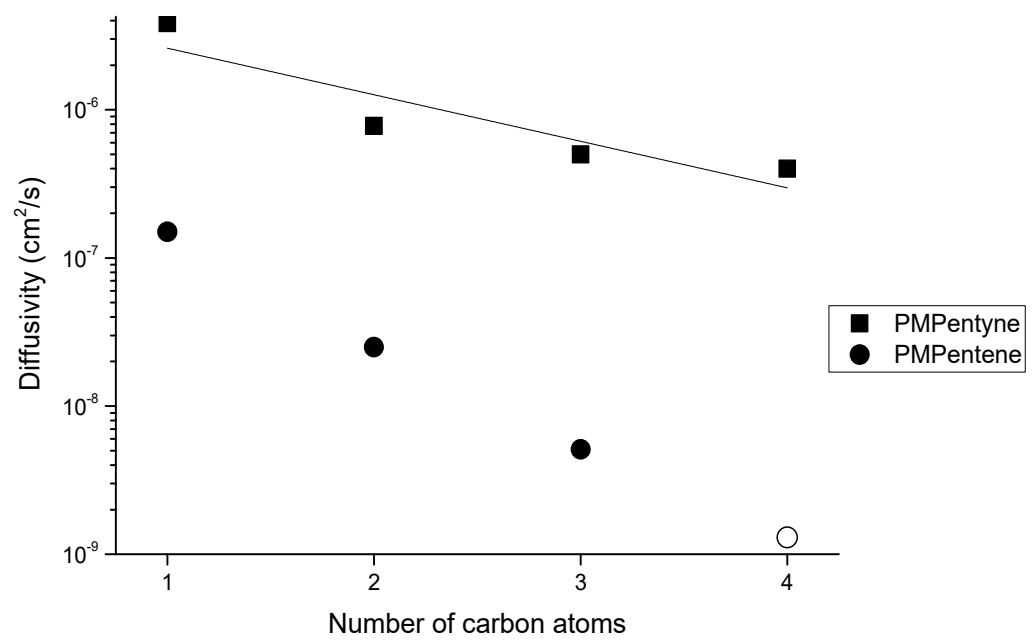

Figure 5. Diffusion coefficients of PMPentyne and PMPentene at $10{ }^{\circ} \mathrm{C}$ : data calculated from $D=P / S$, - experimental data; $\bigcirc$ calculated using correlation approach (Equations (7)-(9)).

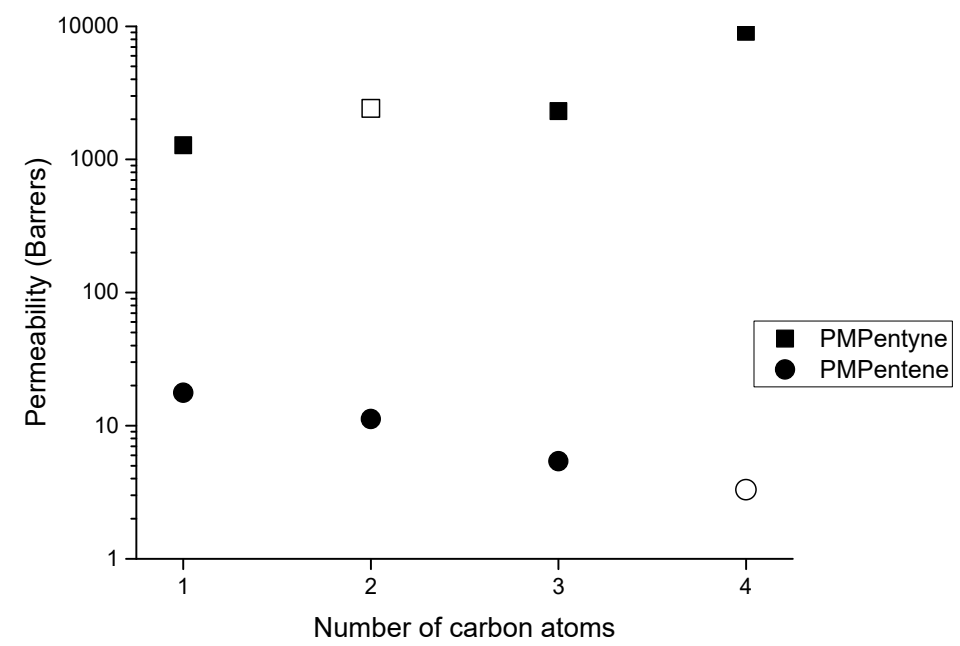

Figure 6. Permeability coefficients of PMPentyne and PMPentene at $25^{\circ} \mathrm{C}$. $\mathbf{\square}, \bullet$ experimental data; $\square$, $\bigcirc$ data calculated using correlation approach (Equations (7)-(9)). 


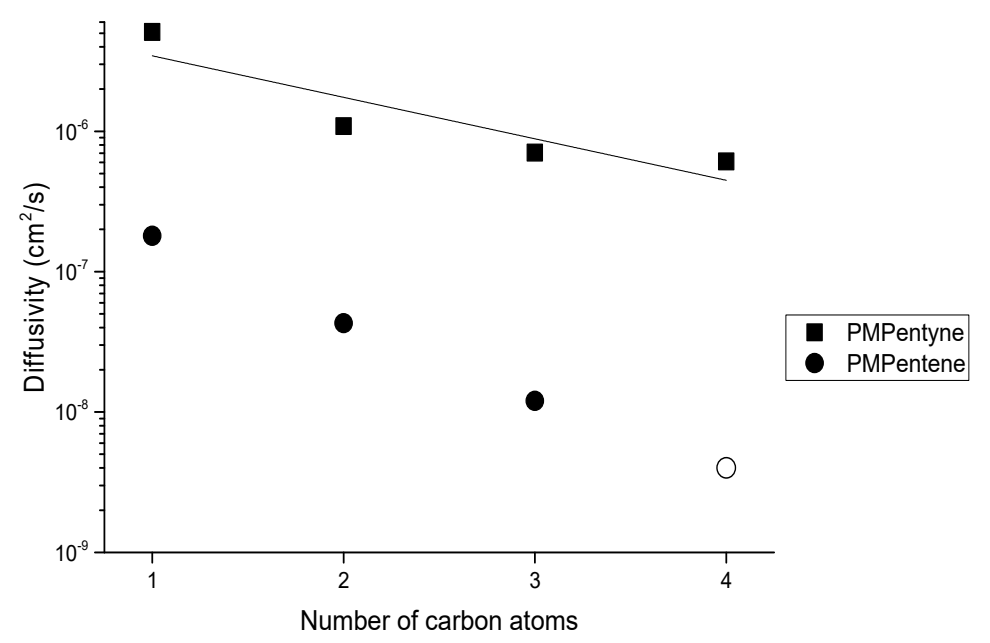

Figure 7. Diffusion coefficients of PMPentyne and PMPentene at $25^{\circ} \mathrm{C}:$ data calculated from $D=P / S$, - experimental data; $\bigcirc$ calculated using correlation approach (Equations (7)-(9)).

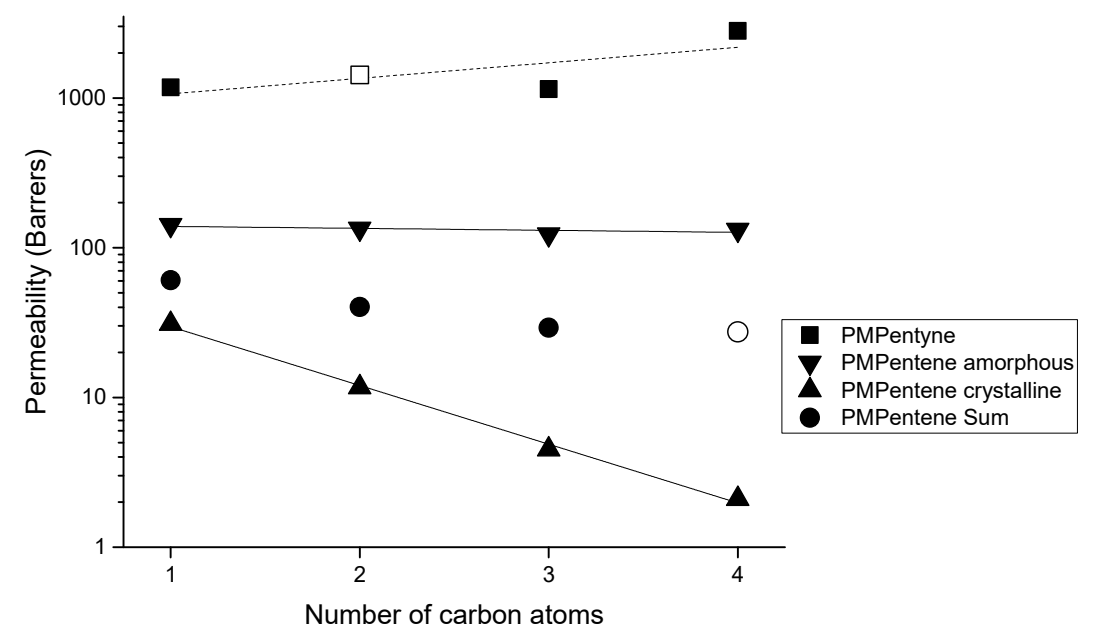

Figure 8. Permeability coefficients of PMPentyne and PMPentene (with amorphous-crystalline dispersion) at $80{ }^{\circ} \mathrm{C}$ : $\bullet$ experimental data; $\mathbf{\Lambda}, \mathbf{v}$ data calculated using two-phase model (Equations (2) and (3)); extrapolated from experimental data; $\square, \bigcirc$ data calculated using correlation approach (Equations (7)-(9)).

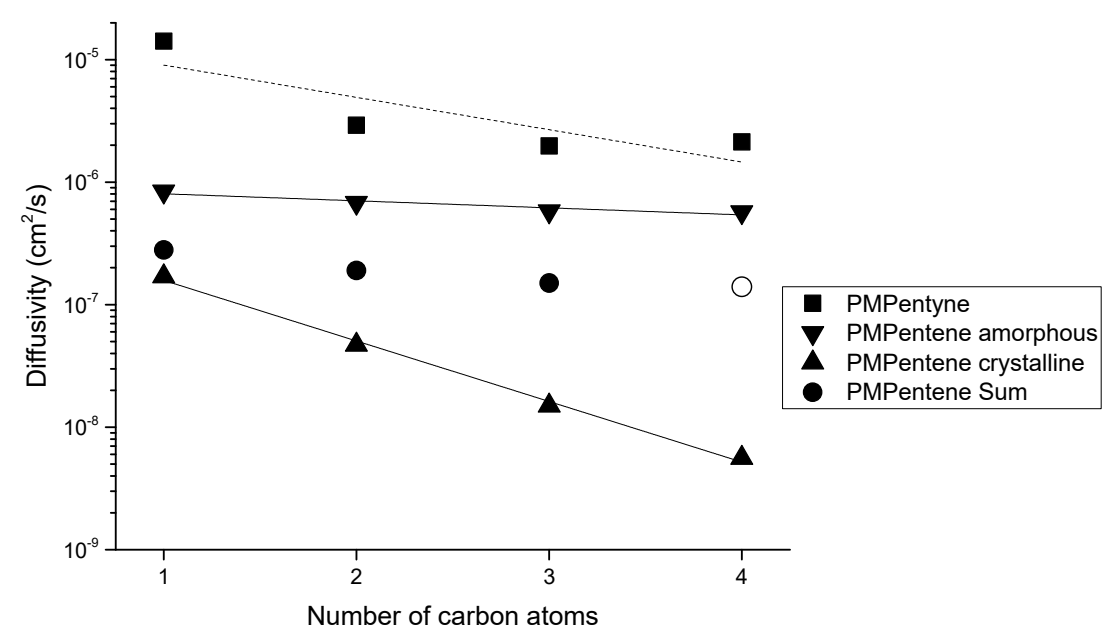

Figure 9. Diffusion coefficients of PMPentyne and PMPentene (with amorphous-crystalline dispersion) at $80{ }^{\circ} \mathrm{C}$ : • experimental data; $\boldsymbol{\Lambda}, \boldsymbol{\nabla}$ data calculated using two-phase model (Equations (2) and (3)); - data calculated from $D=P / S ; \bigcirc$ calculated using correlation approach (Equations (7)-(9)). 
Thus, the combination of experimental and theoretical approaches allowed observation of the change in the permeability properties of these polymers in the temperature range $10-80{ }^{\circ} \mathrm{C}$, which includes the $\mathrm{T}_{\mathrm{g}}$ of PMPentene. It can be seen from Figures 8 and 9 and Tables 3 and 4 that the selectivity of the diffusion and permeability of PMPentene crystalline phase exceeds these parameters for the amorphous phase at $80^{\circ} \mathrm{C}$, which must be taken into account when using PMPentene membranes at temperatures above $T_{g}$. It can be seen from Figures $4-9$ that despite the similar physical densities of the studied polymers and their chemical structures there is a significant difference in permeability levels (2-3 orders of magnitude) and opposite trends in separation selectivity. It is worth noting that PMPentene is a methane-selective polymer and PMPentyne is a butane-selective polymer throughout the studied temperature range (Tables 6 and 7). Note that as the temperature decreases, the permeability of butane in PMPentyne increases, but in PMPentene butane permeability decreases (Figures 4, 6 and 8). These two different trends can be explained as follows: PMPentyne has a high free volume, which is available for gas diffusion and includes microcavities of about 5-10 ̊ in size. This leads to diffusion coefficients similar to those in porous media. In addition, as shown above (Tables 6 and 7), the diffusion selectivity for PMPentyne is significantly lower than that for PMPentene. Thus, the diffusion restrictions are weaker in the case of PMPentyne and separation selectivity is no longer strictly determined by diffusion, but by the dominant solubility of butane in the polymer (Tables 5-7). PMPentene has smaller free volume cavities (about $4 \AA$ in size), which are less available for gas molecules, and the diffusion process is more difficult in comparison to that in PMPentyne. This leads to an increased selectivity of diffusion (see above), which in this case is determined by the size of the molecules.

Table 6. Selectivity of butane/methane for PMPentyne.

\begin{tabular}{cccc}
\hline & $\mathbf{1 0}{ }^{\circ} \mathbf{C}$ & $\mathbf{2 5}^{\circ} \mathbf{C}$ & $\mathbf{8 0}^{\circ} \mathbf{C}$ \\
\hline$\alpha_{P}$ & 10.4 & 7.1 & 2.4 \\
$\alpha_{D}$ & 0.10 & 0.13 & 0.15 \\
$\alpha_{S}$ & 104 & 59.2 & 16 \\
\hline
\end{tabular}

Table 7. Selectivity of methane/butane for PMPentene.

\begin{tabular}{cccc}
\hline & $\mathbf{1 0}{ }^{\circ} \mathbf{C}$ & $\mathbf{2 5}^{\circ} \mathbf{C}$ & $\mathbf{8 0}^{\circ} \mathbf{C}$ \\
\hline$\alpha_{P}$ & 7.7 & 5.3 & 1.85 \\
$\alpha_{D}$ & 114.9 & 45.5 & 2.3 \\
$\alpha_{S}$ & 0.07 & 0.12 & 0.79 \\
\hline
\end{tabular}

\section{Conclusions}

The combination of theoretical approaches and experimental evaluation of the selective permeance parameters of $\mathrm{C}_{1}-\mathrm{C}_{4}$ alkanes in PMPentene and PMPentyne as polymeric media is presented in this work for the first time. It is shown that for highly permeable PMPentyne, the most practical way is to combine experimental permeability evaluation over a certain range of temperatures with theoretical solubility estimation by using the 'hard-spheres' theory. This allows the creation of a complete set of membrane parameters for PMPentyne in relation to $C_{1}-C_{4}$ alkanes (which includes $P, D, S, E_{P}, E_{D}$ and $\Delta H_{S}$ ). It should be noted that diffusion parameters were estimated indirectly because it is impossible to do so experimentally in the case of ultrathin layers or highly permeable polymers (cases that are notable for their low values of time-lag). In the case of PMPentene, diffusion coefficients can be measured experimentally, but there are problems with the analysis of selective gas transfer in semicrystalline media. It is shown that this problem can be solved by application of the two-phase system selective gas transfer theory. Moreover, for the cases when it is impossible to obtain experimental data, correlation analysis of gas permeance parameters in polymers can be used.

The explanation of butane-selective properties revealed in PMPentyne $\left(C_{1}<C_{2}<C_{3}<C_{4}\right)$ and the methane-selective properties of PMPentene $\left(C_{1}>C_{2}>C_{3}>C_{4}\right)$ is presented in this study. It is 
deemed that the combination of methods presented can allow intentional membrane selection for specific oil- and gas-processing mixture separations.

Author Contributions: S.M. is the author of the methodology of the article and contributed in writing-original draft preparation; V.Z. carried out the investigation and contributed in writing-review and editing; T.G. carried out the formal analysis; V.T. created the concept of the article. All authors have read and agreed to the published version of the manuscript.

Funding: This work was supported by a joint grant of Russian Science Foundation (RSF) №19-49-04105 and Deutsche Forschungsgemeinschaft (DFG)-No. GR 1311/94-1 (poly (4-methyl-1-pentene)), and by State Program of TIPS RAS (poly (4-methyl-2-pentyne)).

Acknowledgments: Experiments were carried out using equipment of the TIPS RAS Center of collective use "New petrochemical processes, polymeric composites and adhesives".

Conflicts of Interest: The authors declare no conflict of interest.

\section{Nomenclature}

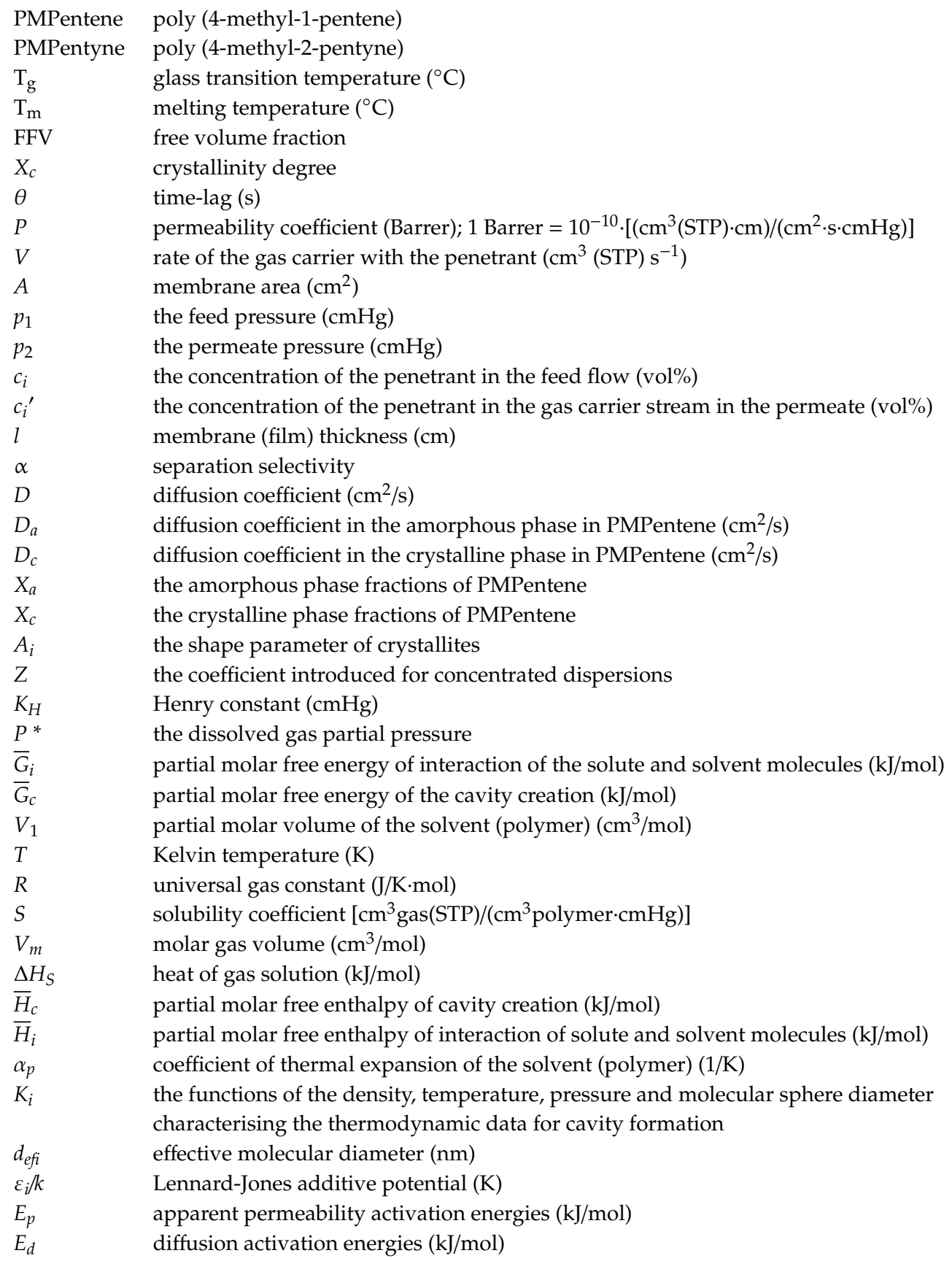




\section{References}

1. Kleiner, V.I.; Shishatskii, S.M.; Yampol, S.; Kevdina, I.B.; Kuz'min, N.N.; Krentsel, B.A. Permeability of poly(4-methyl-1-pentene) with different degrees of isotacticity. Polym. Sci. 1993, 35, 1403-1406.

2. Buhler, K.U. Heat and Heat Resistant Polymers; Chemistry: Moscow, Russia, 1984.

3. Krentsel, B.A.; Kissin, Y.V.; Kleiner, V.J.; Stotskaya, L.L. Polymers and Copolymers of Higher $\alpha$-Olefins; Hanser: New York, NY, USA, 1997.

4. Puleo, A.C.; Paul, D.R.; Wong, P.K. Gas sorption and transport in semicrystalline poly(4-methyl-1-pentene). Polymer 1989, 30, 1357-1366. [CrossRef]

5. Lopez, L.C. Synthesis, structure and properties of poly(4-methyl-1-pentene). J. Macromol. Sci. Part C 1992, 32, 301-406. [CrossRef]

6. Peek, G.; Killer, H.; Reeves, R.; Sosnoski, A.W.; Firmin, R.K. Early Experience with a Polymethyl Pentene Oxygenator for Adult Extracorporeal Life Support. ASAIO J. 2002, 48, 480-482. [CrossRef]

7. Kostrov, J.A.; Mostova, G.B.; Ignatienko, T.; Arbashnikov, A.J.; Khutorski, B.J. Gas separating graviton yarn. Chim. Volok. 1986, 6, 49.

8. Yushkin, A.; Grekov, A.; Matson, S.; Bermeshev, M.; Khotimsky, V.; Finkelstein, E.; Budd, P.M.; Volkov, V.; Vlugt, T.J.H.; Volkov, A. Study of glassy polymers fractional accessible volume (FAV) by extended method of hydrostatic weighing: Effect of porous structure on liquid transport. React. Funct. Polym. 2015, 86, $269-281$. [CrossRef]

9. Morisato, A.; He, Z.; Pinnau, I. Mixed-gas permeation properties and physical aging of poly(4-methyl-2-pentyne). In Polymer Membranes for Gas and Vapor Separation; Freeman, B.D., Pinnau, I., Eds.; ACS Symposium Series: Washington, DC, USA, 1999; pp. 56-67.

10. Yakovlev, A.V. Biobutanol Vapour-phase Concentrating by Application of Polymeric Membranes Based on poly(1-trimethylsylyl-1-propyne) and poly(4-methyl-2-pentyne). Ph.D. Thesis, TIPS RAS, Moscow, Russia, 2012.

11. Sultanov, E.Y.; Ezhov, A.A.; Shishatskiy, S.M.; Buhr, K.; Khotimskiy, V.S. Synthesis, characterization, and properties of poly(1-trimethylsilyl-1-propyne)-block-poly(4-methyl-2-pentyne)blockcopolymers. Macromolecules 2012, 45, 1222-1229. [CrossRef]

12. Teplyakov, V.; Meares, P. Correlation aspects of the selective gas permeabilities of polymeric materials and membranes. Gas Sep. Purif. 1990, 4, 66-74. [CrossRef]

13. Markova, S.Y.; Beckman, I.N.; Teplyakov, V.V. Diffusion of C1-C3 alkanes in semicrystalline poly(4-methyl-1-pentene) as a two-phase polymeric system. Int. J. Membr. Sci. Technol. 2017, 4, 28-36.

14. Yave, W.; Shishatskiy, S.; Albetz, V.; Matson, S.; Litvinova, E.; Khotimskiy, V.; Pienemann, K.-V. A Novel Poly(4-methyl-2-pentyne)/TiO 2 Hybrid Nanocomposite Membrane for Natural Gas Conditioning: Butane/Methane Separation. Macromol. Chem. Phys. 2007, 208, 2412-2418. [CrossRef]

15. Zhmakin, V.V.; Teplyakov, V.V. The evaluation of the C1-C4 hydrocarbon permeability parameters in the thin film composite membranes. Sep. Purif. Technol. 2017, 186, 145-155. [CrossRef]

16. Beckman, I.N.; Shalygin, M.G.; Teplyakov, V.V. Particularities of membrane gas separation under unsteady state conditions. In Mass Transfer in Chemical Engineering Processes; Markoš, J., Ed.; InTech: Rijeka, Croatia, 2011; pp. 205-232.

17. Beckman, I.N.; Teplyakov, V.V. Selective gas transfer through binary polymeric system based on block-copolymers. Adv. Colloid Interface Sci. 2015, 222, 70-78. [CrossRef] [PubMed]

18. Markova, S.Y.; Gries, T.; Teplyakov, V.V. Poly(4-methyl-1-pentene) as a semicrystalline polymeric matrix for gas separating membranes. J. Membr. Sci. 2020, 598, 117754. [CrossRef]

19. Michaels, A.S.; Bixler, H.J. Solubility of Gases in Polyethylene. J. Polym. Sci. 1961, 50, 393-412. [CrossRef]

20. Malykh, O.V.; Golub, A.Y.; Teplyakov, V.V. Polymeric membrane materials: New aspects of empirical approaches to prediction of gas permeability parameters in relation to permanent gases, linear lower hydrocarbons and some toxic gases. Adv. Colloid Interface Sci. 2011, 164, 89-99. [CrossRef]

21. Yampolskii, Y.; Wiley, D.; Maher, C. Novel Correlation for Solubility of Gases in Polymers: Effect of Molecular Surface Area of Gases. J. Appl. Polym. Sci. 2000, 76, 552-560. [CrossRef]

22. Favre, E.; Nguyen, Q.T.; Schaetzel, P.; Clement, R.; Neel, J. Sorption of organic solvents into dense silicone membranes. Part 1. Validity and limitations of Flory-Huggins and related theories. J. Chem. Soc. Faraday Trans. 1993, 89, 4339-4346. [CrossRef] 
23. Favre, E.; Nguyen, Q.T.; Clement, R.; Neel, J. The engaged species induced clustering (ENSIC) model: A unified mechanistic approach of sorption phenomena in polymers. J. Membr. Sci. 1996, 117, 227-236. [CrossRef]

24. Jonquieres, A.; Perrin, L.; Durand, A.; Arnold, S.; Lochon, P. Modelling of vapour sorption in polar materials: Comparison of Flory-Huggins and related models with the ENSIC mechanistic approach. J. Membr. Sci. 1998, 147, 59-71. [CrossRef]

25. Lue, S.J.; Tsai, C.L.; Lee, D.T.; Mahesh, K.P.O.; Hua, M.Y.; Hu, C.C.; Jean, Y.C.; Lee, K.R.; Lai, J.Y. Sorption, diffusion, and perm-selectivity of toluene vapor/nitrogen mixtures through polydimethylsiloxane membranes with two cross-linker densities. J. Membr. Sci. 2010, 349, 321-332. [CrossRef]

26. Volkov, V.V. Free Volume Structure and Transport Properties of Glassy Polymers-Materials for Separating Membranes. Polym. J. 1991, 23, 457-466. [CrossRef]

27. Beckman, I.N.; Golub, A.Y.; Yakovlev, A.V.; Teplyakov, V.V. Noble gases as Indicators of molecular-selective gas transport in polymeric membranes. Pet. Chem. 2013, 53, 460-470. [CrossRef]

28. De Ligny, C.L.; van der Veen, N.G. A test of Pierotti's theory for the solubility of gases in liquids, by means of literature data on solubility and entropy of solution. Chem. Eng. Sci. 1972, 27, 391-401. [CrossRef]

29. Starannikova, L.E.; Teplyakov, V.V. Gas permeability of poly(1-trimethylsilyl-1-propyne): Estimation of experimental data and calculated parameters. Polym. Sci. Ser. A 1997, 39, 1690-1696.

30. Pierotti, R.A. The Solubility of Gases in Liquids. J. Phys. Chem. 1963, 67, 1840-1845. [CrossRef]

31. Zhmakin, V.V.; Shalygin, M.G.; Khotimskiy, V.S.; Matson, S.M.; Teplyakov, V.V. Non-additive separation selectivity enhancement in poly(4-methyl-2-pentyne) in relation to C1-C4-alkanes. Sep. Purif. Technol. 2019, 212, 877-886. [CrossRef]

32. Merkel, T.C.; Freeman, B.D.; Spontak, R.J.; He, Z.; Pinnau, I.; Meakin, P.; Hill, A.J. Sorption, transport, and structural evidence for enhanced free volume in poly(4-methyl-2-pentyne)/fumed silica nanocomposite membranes. Chem. Mater. 2003, 15, 109-123. [CrossRef]

33. Morisato, A.; Pinnau, I. Synthesis and gas permeation properties of poly(4-methyl-2-pentyne). J. Membr. Sci. 1996, 121, 243-250. [CrossRef] 